\title{
Amat Romanında Yeni Tarihselcilik
}

\section{ASLI YÜKSEL*}

\section{Öz}

1980 sonrası gelişen Yeni Tarihselcilik, tarihin kurgusal boyutu üzerine odaklanır. Metinleri ait oldukları kültür ve coğrafyadan soyutlayarak değerlendiren eleştiri yöntemlerinin aksine Yeni Tarihselci söylem, metinlerin oluştuğu sosyal, kültürel, siyasî ve edebî atmosferi de dikkate almıştır. Yazar-devir-eser üçlüsüne bakıldığında temeli tarihe dayanan ancak özünde kurgulanmış ve yorumlanmış bir tarihi ortaya çıkaran bu kuram tarihi yenileyerek yazmayı irdeler. Dekor olarak kültürü, coğrafyayı, dönemi, alanı, tarihî parçaları seyir içinde veren yapısı ile İhsan Oktay Anar'ın Amat eserine Yeni Tarihselcilik üzerinden bakılabilir. Teknik ilkeler üzerinde durularak romanın olay örgüsü, karakterler ve sonucu bağlamında kuramın romandaki görünümü tespit edilmeye çalışılacaktır.

Anahtar sözcükler: Yeni Tarihselcilik, Metinlerarası, Üstkurmaca, İhsan Oktay Anar, Amat

\section{Abstract}

New Historicism developed after 1980, focuses on the fictional dimension of history. Unlike the methods of criticism evaluating the texts abstracting from geography and culture which they belong to, new historicist discourse considers social, cultural, political and literary atmosphere that the texts create. Looking at the trio of the author-the period-the work, this theory aims to reveal the fictionalized and interpreted history, and to scrutinize the rewriting processes in historiography. With its structure which presents the culture, geography, period and historical

\footnotetext{
* Nevşehir Hacı Bektaş Veli Üniversitesi Sosyal Bilimler Enstitüsü, aslierginyuksel@outlook.com
} 
factors as a décor in a fluent and coherent way, Oktay Anar's work named Amat can be viewed through New Historicism. By focusing on the technical principles, the appearance of the theory on the novel will be analyzed in the context of novel's plot, characters and result.

Keywords: New Historicism, Intertextuality, Metafiction, İhsan Oktay Anar, Amat

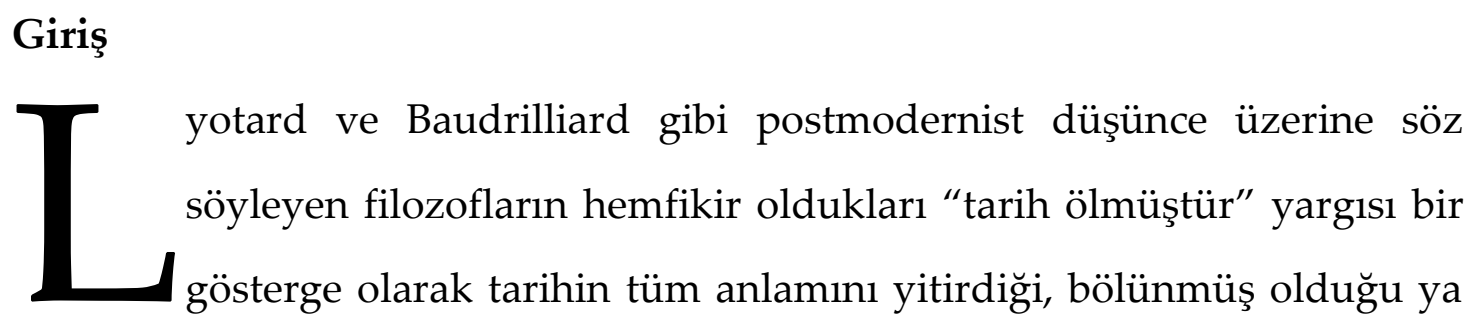
da göndergelerden ayırt edilemez hâle geldiği için artık kendisi dışında hiçbir şeye gönderme yapamadığı anlamına gelmektedir. Bir başka deyişle "tarih ölmüştür" söylemi, tarihin artık meşrulaştırıcı bir arka plan olarak işlev göremeyeceğini belirtir (Uğurlu 2009: 14). Bunu daha iyi anlayabilmek için de postmodern tarih yazımına bakmak gerekir. Bu anlayış da tarihin gerçek bir tarihsel geçmişe gönderme yaptığını yadsıyarak tarihin de kurmaca olduğunu iddia eder. Edebî eserleri edebî olmayan metinlerin 1şığı altında açılamaya çalışan bu yaklaşım, Catherine Gallagher ve Stephen Greenblatt önderliğinde çıkarılan Representation dergisi etrafındaki kuramsal sorgulamalardan doğmuş bir inceleme yöntemidir (Yeşilyurt 2009: 1990). Metinleri

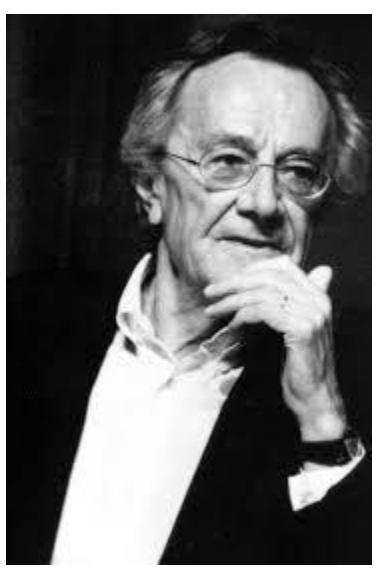

Jean-François Lyotard ait oldukları kültürel daireden soyutlayarak değerlendiren eleştiri yöntemlerinin aksine Yeni Tarihselcilik, metinlerin oluştuğu bağlamı ele almıştır. Bu bağlamdan hareketle zaman, olay ve kişiler üzerinden hayal-hakikat arasında kalan kurgulanmış bir metin ortaya çıkar.

Buradan hareketle Yeni Tarihselci edebî yöntemin bu dairedeki teknik ve ilkelerinin Amat'ta nasıl somutlaştığını ortaya koymak çalışmanın esasını oluşturmaktadır. 


\section{Yeni Tarihselcilik ve Amat}

Peygamber Efendimizin ve onun tebliğ ettiği kitaba iman edenlerin Mekkeli putperestlerden gördükleri ezâ ve cefâ nedeniyle Medine'ye hicretinden 1080-1082 yıl, İsa Aleyhisselâmdan ise 1670 yıl sonra, Şevval ayının üçüncü gecesinde (Anar 2014: 9) Deli Marangoz Nuh Usta'nın, Ayyaş Ohannes tarafından vaftiz edilmesi ve 247 akçe almasıyla kurgusal temeller atılır. Romanın ilk sayfalarında tarihe doğru

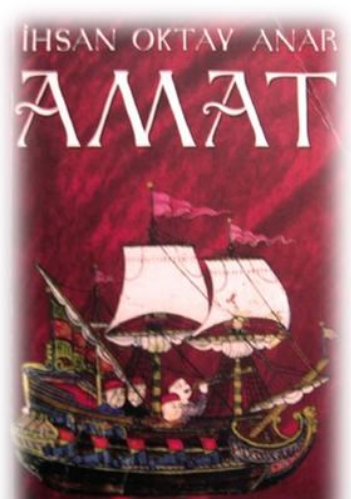
kurgulanmış bir dünyaya sürüklenme başlar. 247 kişilik mürettebatla İstanbul'dan Navarin'e doğru hareket eden bu gemi salı gününün uğursuzluğuyla olağanüstü olayların mekânı hâline gelir. Kırbaç Süleyman'ın Tefriciye kasabasındaki camiyi yıkma emrini vermesiyle Koca Reisliğe geçmesi, Süleyman'ın ölümsüzlük arayışı, Nuh Usta'nın mürettebata fal bakarak öldürdükleri kişileri bilmesi, Venedik gemisiyle çatışma, siyah bir bayrağın göndere çekilerek günahkârları taşıyan bir gemi olduğuna işaret, Malta Adası'na sığınma, veba hastalığının gemide yayılmasıyla alınlarında Amat yazısıyla kireçlenmesi devamında Kırbaç Süleyman'ın her şeyi anlayarak şeytanın gemisini Amat isminden Mat (ölüm) ismine dönüştürmesiyle geminin paramparça olması ve sonunda "Bu anlatılanlar gerçek miydi?" sorusuyla okuyucuyu hayal-hakikat kararsızlığına sürükler. Roman içerisinde yer alan şahıs ve kitaplar -yazar tarafından kurgulanmış olsa da- okuma esnasında gerçek bir dünya olduğunu kanıtlamaya çalışan parçalardır. Bu bağlamda Yeni Tarihselci inceleme yönteminin en temel ilkeleri ile İhsan Oktay Anar'ın Amat adlı romanı arasında paralellik olduğu görülmektedir.

Bu çerçevede eserde yer alan Yeni Tarihselci unsurlar şunlardır:

\section{Bağlam}

Geçmiş, üretilen tarih söylemi içinden çıktı̆̆ı kültürel oluşumlara, yere, zamana göre metinselleştirilir. Yeni Tarihselcilik, tarihsel arka planı ihmal etmeden, bağlamı dikkate alarak geçmişte yaşanan olayları kurgular ve önemsiz, ayrıntı, tuhaf 


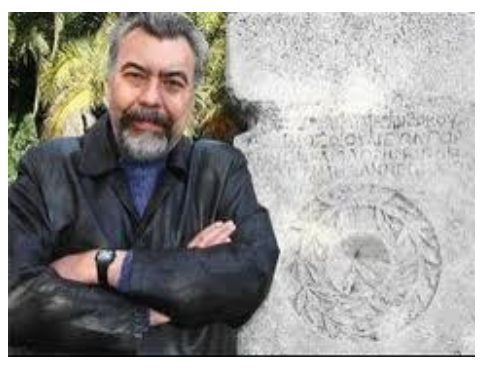

şeyleri ele alırlar; rüyalar, biyografiler, hikâyeler vb. kaynaklar onlar için araştırma konusudur.

İhsan Oktay Anar Amat romanında tarihi, bağlamı yansıtma noktasında dayanak olarak kullanır. Yazar, Konstantiniye şehrinin Galata semtinde başlayan olayda şehrin yaşayışı, geçmiş yaşantılar hakkında giriş yaparak romanın geçtiği zamanı ve mekanı belirtmiştir. Kırbaç Süleyman, Kaptan Diyavol, Marangoz Nuh Usta, İsrafil, Hâbil gibi bilinen isimlerin romandaki varlığı, mitolojik yönleri, kutsal metinlerin izleri, Ruznamçe Kisedâarı Ölügözlü Cuma Bey, Zindan Kâtibi Çapraz Recep Dede Hazretleri, Masraf Kâtibi Kuzgunî Halim Efendi, Vakanüvis Şaşı İkram Efendi, Buhur Mütevellisi Kılbaz Yakup Dede Hazretleri, Selâm Ağası Kekez İsmail Efendi, Müjdecibaşı Kedigöz Âbidin Dede Hazretleri, Galatalı hekim Avram Efendi gibi isimlerin yer alması tarihî aka planı gösterir. Dolayısıyla romanda yer alan isimler, kısa biyografi ve tanıtmalar, mitolojik unsurlar, hastalıklar, kitaplar bağlamın parçalarıdır.

\section{Prolog}

Roman yazarı, gerçeklik derecesini artırmak için olaya edebî yorumla değil, doğrudan bir alıntıyla başlayabilmekte ve romanını bu alıntıyı merkeze alarak sürdürüp bitirebilmektedir (Yeşilyurt 2015: 1817). Yapılan alıntı romanın bitiminde daha anlamlı hâle gelir ve romanın kurgusunu tek cümle ile ifade etme görevini üstlenmiş olur.

Tekvin'den “Kendine Gofer ağacından bir gemi yap; gemide odalar yapacaksın ve onu içeriden ve dışarıdan ziftle ziftleyeceksin" (Tekvin, 6: 14) sözü, kitabın başlangıcında anlatımdan ayrı gibi görülse de aslında olay hakkında ipucu vermekte ve sonucu içerisinde saklamaktadır. Yazarın romanın başına koyduğu bu alıntı kutsal kitap olarak kabul edilen Eski Ahit'in (Tevrat ve Zebur) ilk bölümü olan Tekvin'den (Yaratılış) alınmıştır. Bu parçanın neden seçildiği ve hangi amaçla yazar tarafından roman metninin başına konulduğu, ilk başta anlaşılmamaktadır. Aslında 
bu okuyucuyu baştan uyaran bir işarettir ve bu işaretin işlevini ortaya çıkaracak, metinle bağlantısını bulacak olan da okuyucudur. Yaratılış kitabı bize evrenin ve insanın yaratılışını, günahın ve dünyada çekilen acıların başlangıcını, Tanrı'nın insanlığa yaklaşım biçimini anlatmaktadır. Bu bağlamda yer verilen alıntı, Tanrı'nın Nuh Peygamber'e olan buyruğunu işaret eder. Tanrı, insanları yaptıkları kötülükler, işledikleri günahlar sonucunda yeryüzünden yok etmeye karar verir ve bunun için yeryüzüne tufan gönderir. Fakat doğruluğundan dolayı Nuh Peygamber'in ailesini ve hayvan soylarını kurtarmaya karar verir ve tufanda sağ kalmaları için bir gemi yapmasını buyurur. Romanın başındaki bu alıntı, elbette ki romanın büyük ölçüde geçtiği mekân olan Amat adlı gemiye ve sonunda öğrendiğimiz üzere onu Diyavol Paşa'nın emri ile inşa eden marangoz Nuh Usta'ya yapılan bir göndermedir.

Kurgusal bir tarihi anlatmayı amaçlayan Yeni Tarihselcilikte bu alıntı okuyucuyu gerçeğe çekmektedir.

\section{3. İsim Sembolizasyonu}

Kurgu ile gerçeğin iç içe geçtiği romanda en önemli teknik unsurlardan biri kahramanın isimlendirilmeleridir. Bu isimler tarihî, dinî, mitolojik veya kurgusal olabilir. Romanda Diyavol Paşa, Marangoz Nuh Usta, Kırbaç Süleyman, İsrafil, Hâbil isim sembolizasyonunun yapıldığı karakterlerdir. Bu isimler dinî nitelikli olup sadece isimleri değil, aldıkları kişilerin özellik ve güçlerini de bünyelerinde barındırmaktadır.

Roman büyük ölçüde Diyavol ve Kırbaç Süleyman üzerinden kurgulanır. Amat gemisinin kaptanı olan Diyavol Paşa, kitaplarla ve değişik eşyalarla dolu bir odadan her şeyi kontrol eder. Gemide sadece Kırbaç Süleyman ve Nuh Usta ile görüşür. Ölümsüzlük konusunda oldukça meraklı ve bunun arayışında olan Kırbaç Süleyman Diyavol Paşa'nın kitaplarında bunun sırrını ararken dokunmaması gereken kara kaplı defteri açarak "Ruhunu Diabolos'a sat" (Anar 2014: 213) şifresini çözer ve Diyavol Paşa'nın isim benzerliğiyle şeytan olduğunu anlar. Savaş zamanlarında kaybolması, giydiği kıyafetler şeytan olmasına ima iken Süleyman'ın 
okuduğu kitap ile şifreyi çözmesi şeytan olduğunun ispatı olur. Diyavol Paşa'dan sonra en yetkili kişi olan ve Kocareis unvanını kazanan Kırbaç Süleyman da oldukça sert mizaçlı ve mürettebata sözünü geçiren bir kişidir. Gemi yolculuğunda “Ey rüzgâr! Dur artık dur!”(101) sözüyle yağmura hükmetmek istemesiyle Hz. Süleyman'a benzetilmiştir. Marangoz Nuh Usta, Diyavol Paşa'nın emriyle Navarin'deki mezarlıktan aldığı 247 meşe

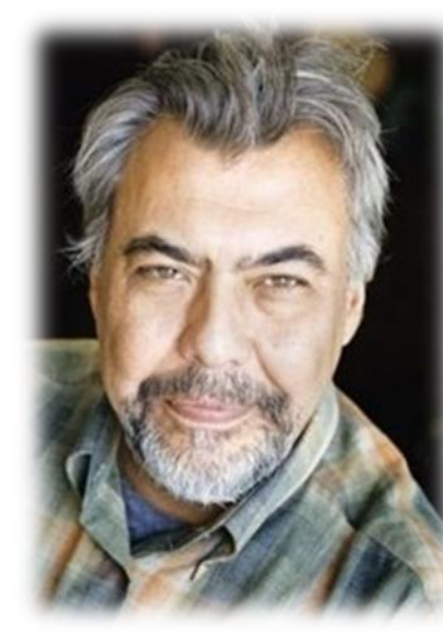
ağacıyla bir gemi yapar. Nuh Usta, Hz. Nuh'a benzetilerek bir gemi inşa etmesi ve yeni hayatın yeni umudu olan canlılar yerine günahkarları taşıyan bu geminin marangozu olması sebebiyle şeytanın yardımcısı olarak görülmektedir. İsrafil yaşı küçük olan ve ayak işlerinden kurtulmak için, oldukça zor bir görev olan geminin borusunu çalmayı başarmıştır. Savaş emrinin verilmesiyle öten bu boru her yerden duyulabilecek kuvvettedir. Dolayısıyla dört büyük melekten biri olan ve Sur'a üflemekle görevlendirilen melekle özdeşleştirilmiştir. Son olarak İbrahim'in yamağ1 olan Hâbil ise esir bir şovalyeye Kur'an'dan âyet okuduğu sırada bir kalemle suçsuz yere öldürülür. Bu da Kâbil'in Hâbil'i suçsuz yere öldürmesine benzetilir.

\section{Metinlerarasılık}

Farklı metinlerin iç içe geçmesi, böylece yeniden üretilmesi olarak tanımlanan metinlerarasılık, postmodern edebiyatın temel yapıtaşlarından biri olarak kabul edilir. Metni, kendi içinde başka metinlerin izlerini taşıyan bir göstergeler ağı olarak düşünen yapısalcılar ve sonrası için, her metin birbirinin devamıdır, kendi içinde başka metinlerin izlerini taşır (Aktulum 2007: 15). Metnin anlaşılabilmesi için hem metinselleşen tarihin hem de bağlamın açığa kavuşturulması ilkesini hareket noktası alan Yeni Tarihselcilik, metinlerarasılık ile edebî eserler bir bütün hâline gelir ve gerçeklik duygusu kazandırılır. 


\section{a. Kolaj ve Alıntı}

Kolaj, yapıştırma, monte etme, gönderge metinlerden alınan parçaların ana metinde bir araya getirilmesi olarak tanımlanır. Metnin dinî, tarihî, felsefi ve masalsı atmosferini destekleyen önemli unsurlardan olan kolaj tekniği romanda doğrudan alıntılar, söz ya da olayın sezdirilmesi ve farklı malzemelerle sağlanmaktadır. Bu bağlamda yazar Amat'ta birçok ayet ve hadise gönderme yapmakta ve alıntılamaktadır.

İlk olarak “Kendine Gofer ağacından bir gemi yap; Gemide odalar yapacaksın ve onu içeriden ve dışarıdan ziftle ziftleyeceksin." Eski Ahit'in (Tevrat ve Zebur) ilk bölümü olan Tekvin'den (Yaratılış) alınmıştır.

Diyavol Paşa'nın kocareisi seçmesi sırasında olan olaylar Kur'an'da yer alan 'şeytanın huzurdan kovulması'nın kurgulanışıdır. Diyavol Kırbaç Süleyman'ı kocaresiliğe seçeceğini söylediğinde Diyavol’un kamarasındaki kişilerin “Gemide bozgunculuk edip kan dökecek birini mi kendine vekil seçiyordun" sözlerine karşılık Diyavol Paşa'nın “Ben sizin bilmediklerinizi de bilirim” (Anar 2014: 74) sözleri Kuran'daki “Hatırla ki Rabbin meleklere: Ben yeryüzünde bir halife yaratacağım, dedi. Onlar: Bizler hamdinle seni tesbih ve seni takdis edip dururken, yeryüzünde fesat çıkaracak, orada kan dökecek insanı mı halife kılıyorsun? dediler. Allah da onlara: Sizin bilemeyeceğinizi herhâlde ben bilirim, dedi." (Bakara Sûresi, 30) ifadeleri ile büyük benzerlik göstermektedir. Bu konuşmalardan sonra kendisinin Süleyman Reis'ten daha hayırlı bir kişi olduğuna inanan Ali Reis, öfkesinden “Ben, kendimden daha aşağı birinin emirlerini dinlemem. Hele Süleyman denilen o cahilin! Asla!" der (Anar 2014: 74). Ali Reis'in bu dediklerinden sonra öfkelenen Diyavol Paşa, ona dönerek şöyle konuşur: “Bu ne küstahlık. Sen kim olduğunu sanıyorsun da emirlerimi dinlemiyorsun! Burada emre karşı gelen asilere yer yok! İsyana izin vermem. Şu andan itibaren artık reis bile değilsin! Seni buradan atıyorum. Artık tayfayla baş kasarada kalacaksın. Adi bir gabyar gibi seyir güvertesine adım bile atamayacaksın." (74) Ali Reis'in Diyavol Paşa'nın emrine itaat etmeyişi, Kur'an-1 Kerim'de şeytanın Âdem'e secde etmeyişini akıllara getirmektedir. Allah, Âdem'i 
yaratınca bütün meleklere secde etmesini söyler; ancak şeytan ona secde etmez ve şöyle der: "Ben ondan daha hayırlıyım. Beni ateşten yarattın, onu ise çamurdan yarattın." (Sâd Sûresi, 76) Bunun üzerine Allah, şeytanı huzurundan kovar: "Allah: Çık oradan (cennetten), sen artık kesinlikle kovulmuş birisin. Ve ceza gününe kadar lanetim üzerinde olsun" (Sâd Sûresi, 77-78.) buyurmuş̧tur. Ali Reis, dışarı atılırken: “Asıl sen şunu bil ki nerede olursam olayım, seçtiğin bu adamı düşman belleyeceğim... Andolsun ki onu mahvetmek için elimden geleni yapacağım. Bu konuda seninle bahse bile tutuşabilirim! Çıktığımız şu uğursuz seferin sonuna kadar mühlet ver bana! İşte o zaman göreceksin, kendine vekil seçtiğin bu yaratığın ne mal olduğunu!" (Anar 2014: 75) Ali Reis'in bu sözleri, Kur'an-1 Kerim'de huzurdan kovulan şeytanın haykırışı gibidir: “İblis, "Ey Rabbim! Öyle ise bana insanların diriltilecekleri güne kadar mühlet ver." dedi. Allah şöyle dedi: 'Sen o bilinen vakte (kıyamet gününe) kadar mühlet verilenlerdensin.' İblis, ‘Senin şerefine andolsun ki, içlerinden ihlâslı kulların hariç, elbette onların hepsini azdıracağım.' dedi." (Sâd Sûresi, 79-83)

Süleyman Paşa, Diyavol'un kamarasındaki okuduğu kitaplarda ölümsüzlüğe erişmenin şifresini araken "Her nefsin ölümü tadacağ şu dünyada herkesin aslında ölümsüz olduğunu göstermek, iç bulantısını ikiye katlıyordu" (Anar 2014: 116) ifadesi ile Kuran'daki “Her nefis ölümü tadacaktır” (Âl-i İmrân Sûresi, 185- Enbîya Sûresi, 35) ayeti ile benzerdir.

Kırbaç Süleyman'ın “Velisüleymânerrıyha âsıfeten tecriy biemrihî ilel'ardılletiy bâreknâ fiyha!/Kasırga gibi esen rüzgârı Süleyman'ın emrine verdik!" (Anar 2014: 100; Enbiyâ Sûresi, 81) ifadelerine yer verilmiştir.

Romanda esir edilen şövalye, İslam dinini öğrenmek için İbrahim Bey'den Kur'an-1 Kerim ile kağıt ve divit ister. İbrahim Bey de Hâbil'e hastanın yanında kalmasını ve ona hidayet telkin etmesini söyler. Şövalye, Kur'an'a bakarken Hâbil'e altı çizili satırların anlamını sorar. Hâbil de satırları okur: "Ve minennâsi men yekuûlü amenna billâhi ve bilyevmil'âhıri ve mâ hüm bimü'miniyn./Insanlardan 
öyleleri vardır ki, inanmadıkları hâlde, 'Allah'a ve ahiret gününe inandık,' derler (Anar 2014: 152; Bakara Sûresi 14) olarak çevirir.

Amat'a iki gemi saldırınca herkes ne olduğunu şaşırır; çünkü kendilerine saldıran gemilerde Osmanlı sancağı çekilidir. Bu sırada Diyavol Paşa, gemidekilere dönerek şöyle der: “Bizler Allah’ın emrini yerine getireceğiz. Bakara Sûresinin 197. ayetinde ne yazıyor, bilen var mı?" (Anar 2014: 176) Geminin güvertesindekiler susunca, bir ihtiyar ayeti ezberden okur: "Femeni'tedâ aleyküm fa'tedü aleyhi bimisli ma'tedâ aleyküm/Kim size saldırırsa siz de tıpkı onun saldırdığı gibi ona saldırın (Anar 2014: 178; Bakara Sûresi 197)

Romanda Süleyman ile olan mücadelesini kaybeden ve bu yüzden ambara atılan Ali Reis'in Süleyman Reis'e “yasak kitabı” okumasını telkin ettiği bölümde, ona “Diyavol'un kamarasındaki kitaplar çok ilgini çekti, değil mi?" diye sorar (Anar 2014: 220). Ardından da ölümsüzlük için yalnız bir kitap okumasını söyler. Ali Reis'in bu sorusuyla Kur'an-1 Kerim'de şeytanın Âdem'i kandırmak için sorduğu soru oldukça benzerdir: "Sonunda şeytan onu kötü düşünceye saptırdı. 'Sana sonsuzluk ağacını ve zeval bulmayan bir mülkü göstereyim mi?'” (Tâhâ Sûresi, 120) Sonrasında kaptan Diyavol Paşa, Süleyman Reis'e yasak olan bir şeye el sürdüğü için güvenini yitirdiğini söyleyerek şöyle der: “Bu gemide artık hiçbir değerin kalmadı... Kıç kasaradaki rahatın da bitti. Hayır! Baş kasarada da kalmayacaksın... Şimdi gideceğin yer değerine uygun olacak!" (Anar 2014: 222) Kur'an-1 Kerim'de de Allah, Âdem'i şeytana uyduğu için cennetten dünyaya gönderir: “'İniniz!' dedi O, 'Kiminiz kiminize düşman olarak belirli bir süreye kadar yeryüzünde yerleşip geçinmek var kaderinizde'"' (A'râf Sûresi, 24)

Eserde, Hikmetü'l Lokman adlı bir eserden “Kelavratotu insanın ömrünü uzatır ama onu ölümsüz yapmaz. İnsana aslında gebreotu yaprağı ölümsüzlük verir. Eskiler gebreotuna, 'kebire' ya da 'kebere' de demişlerdir. Bunun 333. yaprağı eğer gerekenler yapılırsa insanı ölümsüz kılar." (Anar 2014: 192) montajlanmıştır. Ayrıca romanda adı geçen bir başka eser olan Kebire'den de aşağıdaki parçadır: 
ppôan

lôsee

bioui

od $u m l$

itôai (209)

Metne ait olmayan bu şekil ya da grafikler aracılığı ile metnin kurgusallığını ön plana çıkarmış ve yazma eylemini postmodernist bir tutum çerçevesinde oyun hâline getirmiş olan yazar kolaj tekniğini romanın temel parçası olarak kullanmıştır.

\section{b. Dönüştürme, Yansılama (Parodi)}

Gönderge metinle ilişkinin söz konusu olduğu parodide, gönderge metin konu yönünden taklit edilir. Parodi, Kubilay Aktulum için "bir şarkıyı başka bir tonda söylemek"tir (Aktulum 2007: 117). Amacı eğlendirme olan parodinin metne anlamca en yakın olması oldukça önemlidir. Kutsal metinler söz konusu olduğunda bu eğlendirme unsuru, doğrudan değil de dolaylı yollardan sağlanmaktadır. Bu durumda üslup değişeceği için İhsan Oktay Anar, parodiyi hem eğlendirmek, hem de okuyucuyu düşündürerek kurguya bütünlük katmak amacıyla kullanmıştır.

Eserde metinlerarasılık tekniğinin temel dayanak noktalarından biri olan parodi Cellat'ın gemideki katmanlı cehennemi görmesiyle ve Ali Reis'in Kırbaç Süleyman'a olan nefreti ile sağlanmıştır. Eserde, Dante'nin İlahi Komedya adlı eserinin birinci bölümü olan Cehennem ile parodik düzlemde ilişki kurmak mümkündür. İlahi Komedya, Dante Alighieri'nin Cehennem, Araf ve Cennet'e yaptığ1 düşsel bir gezinin öyküsüdür. Ünlü şaire Cehennem yolculuğunda Vergilius rehberlik eder. Rehberi Dante'ye ilk bölümde cehennemi ve orada acı çeken günahkârların durumlarını gösterir. Amat'ta da geminin Cellat'ı ile mahkûmların atıldığ 1 "cehennem" adı verilen hücrede bulunan, Saîr güvertesinden sorumlu, Mâlik adlı biri arasında buna benzer bir yolculuk yaşanır. "Kaygusuz" denilen otla beyni bulanan Cellat, iri yarı bir şahıs olan Mâlik'in rehberliğinde cehennemin altında bulunan güverteleri tek tek dolaşarak burada ıstırap çeken günahkar insanların durumlarını görür (Anar 2014: 
50-54). Eserin bu kısmı ile İlahi Komedya'nın Cehennem'i arasında parodik bir ilişki kurmak mümkündür.

Başka bir bölümde Hz. Âdem'in yaratılışı ve Şeytan'ın Allah'ın emrine karşı gelmesinden dolayı lanetlenip kovulması olayı dönüştürülmüştür. Amat'ta da Kaptan Diyavol kalyonun Koca Reisliğine Kırbaç Süleyman'ı getirmesi üzerine, Ali Reis'in gururundan ötürü onun emrine karşı gelmesi anlatılır. Tıpkı Allah'ın huzurundan kovulan Azazil (şeytan) gibi, Ali Reis de Diyavol'un kamarasından kovulur ve cezalandırılır (74-75). Dolayısıyla bu iki olay arasında parodik bir ilişkiden söz etmek mümkündür. Kovulduktan sonra Hz. Âdem ve insanoğlundan intikam almaya yemin eden Şeytan gibi, Ali Reis de Kırbaç Süleyman'dan intikam almak için uğraşır. Şeytan nasıl Hz. Âdem ve Havva'ya, ebedî hayat vaadiyle yasak meyveyi yedirdiyse, aynı şekilde Ali Reis de sonsuz hayat vaadiyle Süleyman Reis'e Kaptan Diyavol'un yasakladığı kitabı okutur (220).

Genellikle dinî olaylardan ele alınarak kullanılan parodi ile Anar, metnin kurgusallığını vurgulayarak derinliğini ve anlamını çoğaltmıştır.

\section{c. İfade Kalıpları Taklidi, Öykünme (Pastiş)}

Pastiş, gönderge metninin üslup yönünden taklit edilmesidir. Kutsal metinlere öykünüldüğü durumlarda özellikle seslenme, yemin ve tasvir gibi üsluba ait unsurlar taklit edilir (Sarı 2009: 149). Yazar Amat'ta, 1670 yılında denize açllan bir gemide, insan ve şeytan arasındaki mücadeleyi işlemektedir. Anar, bu konuyu işlerken kendisine 17. yüzyılı fon olarak seçmiştir ve kullandığı dil de eserdeki tarihî atmosfere uygun bir biçimdedir. Amat'taki dil, günlük, yaşayan dil değil, yazar tarafından oluşturulmuş, yapma/kurgusal bir dildir. Anar, Osmanlı dönemi halk ve meddah öykülerinde, o dönemde yazılmış tarihsel, dinsel ve felsefi yapıtlarda kullanılan bir dil ve anlatımı benimsemiştir. "Kurşunlu Mahzen Kâtibi Hamamcı Musa Efendi'nin görkemli eseri Tezâkirü’l Mücrimin'de anlatıldığına göre..." (Anar 2014: 11), “Rûznamçe Kisedârı Ölügözlü Cuma Bey'in Kamûsu’l Desais başlıklı eserinde anlatılanlar doğruysa..." (13), "Kuşçubaşı Halifesi Kuyruklu Rıza Çelebi 
Kitabü'l İber başlıklı manzum eserinde anlattıkları doğruysa..." (89), "Selâm Ağası Kekez İsmail Dede Hazretlerinin serdümene verdiği nota kıble, Yedekçi Baba Maymunî İlyas Baba Hazretlerinin El Beyân fî Makasidü'1 Lûtiyân adıyla kaleme aldığı o şahesere göre ise gündoğusuydu." (185) gibi ifadeler, yazarın rivayet üslubu diyebileceğimiz dil ve anlatma geleneğini Amat'ta devam ettirdiği görülmektedir.

Bununla birlikte eserdeki öyküleme yöntemi de diğer eserlerinde olduğu gibi çerçeve öykü (öykü içinde öykü anlatma) tekniği ile kullanılmıştır. Kırbaç Süleyman, Emilio Santos, Aşçıbaşı, İsrafil ve ölümsüzlük otunun öyküsü olmak üzere yer alan iç öykülerle Doğu anlatı geleneklerine bağlı olduğu görülmektedir. Ayrıca alıntılanan ayetler pastiş örnekleridir. Hem üslup hem de kullanılan teknikler bakımından Anar'ın pastiş tekniğini belirgin biçimde kullandığı söylenebilir.

\section{5. Üstkurmaca}

Yazarın, 'yazma eylemi'ni kurmaca metnin bir parçası durumuna getirmesi, 'nasıl yazdığını anlatması' ve romanın içerisinde yazma eylemi ile ilgili sorunlar konusunda düşünce üretmesi, özetle, roman teorisini roman yazma pratiği içerisinde gösterme, edebiyat biliminde üstkurmaca olarak adlandırılmaktadır (Çokluk 2015: 15). Postmodern romanın yapı taşlarından biri olan üstkurmaca; metnin yazılış sürecini, hangi süreçlerden geçtiğini, nasıl yazıldığını, bu süreçte karşılaşılan sorunları ve üretilen çözümleri kurmaca metnin bir parçası durumuna getirmektedir.

Eser “ Zindan Kâtibi Çapraz Recep Dede Hazretleri, Masraf Kâtibi Kuzgunî Halim Efendi, Vakanüvis Şaşı İkram Efendi, Buhur Mütevellisi Kılbaz Yakup Dede Hazretleri, Selâm Ağası Kekez İsmail Efendi, Müjdecibaşı Kedigöz Âbidin Dede Hazretleri, Galatalı hekim Avram Efendi (Anar 2014: 224-226) gibi kişilerin rivayetlerine dayanır. Eserde, olayların başlıca kaynağının Kurşunlu Mahzen Kâtibi Hamamcı Musa Efendi'nin “Galata'nın Karaköy Kapısı civarındaki Balyozdağıtan Hanı'na bitişik, Arap İmam'ın" (224) kahvehanesinin "müdavimleri arasında geçen konuşmalardan ilhamla" (226) yazdığı Tezâkirü'l Mücrimin adlı eser olduğu belirtilmektedir. Dolayısı ile anlatılan olayların arka planında kalsa da metnin yazılış 
süreci eserin konusu hâline gelmiştir. Rıdvan adlı softanın Amat hakkında merak ettiği bilgileri Mahzen Kâtibi Hamamcı Musa Efendi'den öğrenmeye gelmesi metnin kuruluşunu, yazılış sürecini belirginleştirmiştir.

\section{Sonuç}

Yeni Tarihselci söylem, metinlerin gerçekliğini sorgulayarak, geçmişe yönelik anlatılarda hayal-hakikat çatışmasını amaçlar. Böylece okurun zihninde kültürel bir kargaşa oluşur. Geçmiş, edebî metinler için vazgeçilmez bir hazinedir ve sanatçı bu tarihî malzemeyi alır, işler, kullanır, çözümler ve sübjektif yaklaşımıyla değerlendirir. Böylece temeli tarih olan kurgulanmış bir metin ortaya çıar.

Amat'ın sonunda yer alan, Softa'nın "Peki bu hikâye gerçek mi?" sorusuna Musa Kazım'ın "Amat ne kadar gerçekse bu hikâye de o kadar gerçektir." cevabını vermesiyle anlaşılmıştır ki bu kitapta Yeni Tarihselciliğin izleri vardır. Sonuç olarak yazarın amacı tarihi yeni baştan yazmak değil, yazılmış olanı temel alarak, kurgusal bir tarih yazmaktır. Sanatçının eseri bu bağlamda incelenmelidir. Yeni Tarihselcilik, yeni bir tarih uydurmamakla birlikte, yazılmış olanı hayal gücüyle değerlendirerek, arka plandaki tarihin yorumlanabileceğini gösterir. Okuyucu tarafından yapılan doğru bir yorumlama yapıldığı ve okurun tarih algısında ciddi bir dağılma yaşatmadığ1 sürece gerçek görevini (tarih yazımının edebî sorgulanışı) yerine getirmiş olur.

\section{Kaynakça}

Aktulum, Kubilay (2007). Metinlerarası İlişkiler. Ankara: Öteki Yayınevi.

Anar, İhsan Oktay (2014). Amat. İstanbul: İletişim Yayınları.

Çokluk, Necmiddin (2009). İhsan Oktay Anar ve Romanlar Üzerine Bir İnceleme. Yayımlanmamış yüksek lisans tezi. Edirne: Trakya Üniversitesi.

Sarı, Mehmet (2009). Metinlerarası Bă̆lamda İhsan Oktay Anar'ın Romanlarında Kutsal Metinlerin İzleri. Yayımlanmamış yüksek lisans tezi. İstanbul: İstanbul Üniversitesi. 
Uğurlu, Furat (2009). İhsan Oktay Anar'ın Amat Romanında Mitlerin İşlevi. Yayımlanmamış yüksek lisans tezi. İstanbul: Boğaziçi Üniversitesi.

Yeşilyurt, Şamil (2008). “Kurgusal Gerçeğin Gücü: Yeni Tarihselcilik ve Puslu Kıtalar Atlası" 38. ICANAS Uluslararası Asya ve Kuzey Afrika Çalışmaları Kongresi. Ankara: Atatürk Kültür, Dil ve Tarih Yüksek Kurumu Yayınları. s. 1813-1826.

Yeşilyurt, Şamil (2009). "Nedim Gürsel'in Romanlarının Yeni Tarihselci Bağlamda Okunması." Turkish Studies. 4/1-II: 1989-2009. 